\title{
BIOLOGICAL SUSCEPTIBILITY OF EARTH PLASTERS: THE INFLUENCE OF RELATIVE HUMIDITY ON FUNGAL GROWTH
}

\author{
MARIE SOKOLOVÁ*, PAVLA RYPAROVÁ \\ Faculty of Civil Engineering, Czech Technical University in Prague, Thákurova 7, Prague 6, 166 29, Czech Republic \\ *E-mail: mariesokolova@seznam.cz
}

\begin{abstract}
All building materials can be affected by microbiological agents during their lifecycle. The presence of microorganisms changes the appearance of the surface, degrading it, and they can even cause health problems to the residents. The biological susceptibility is dependent on the content of nutrient based on organic compounds. Thus one of the most susceptible of those materials are earthen construction materials. The degree of fungal growth is influenced by the chemical composition and plant fibres additives as well as the external conditions such as temperature and relative humidity.

The earth plastering mortar has started to gain more attention recently as it is considered to have a low environmental impact and to increase the indoor air quality. Mechanical and physical characteristics of earth materials were studied by a number of authors but the knowledge about the biological resistance of the material is scarce.

This study intends to look into the issue of the biological colonisation of earth plasters depending on the relative humidity. The samples, made of four types of earth plasters with different plant fibres, were placed to an environment of the relative humidity ranging from $33 \%$ to $100 \%$. During a period of 4 weeks the extent of fungal growth was observed.
\end{abstract}

Keywords: mould, bacteria, humidity, earth plaster, biodegradation

\section{Introduction}

Earth based building materials have gained more attention recently. In comparison to lime and cement, this natural material is more sustainable, ecological, reusable and locally available. It is easy to produce it and transport it from nearby surroundings, which lowers the budget and has low impact on the environment [1].

The earth material is usually used as a plaster, a render, an adobe or rammed earth. It is known for the ability of absorbing and desorbing water vapour, thus regulating the relative humidity of indoor environment which leads to better indoor air quality and comfort and health of the occupants. People also appreciate the natural colouring and texture of the earth materials [2].

Natural fibres are usually added to the mixture of clay and sand in order to reduce the drying shrinkage, dry bulk density and thermal conductivity [3]. Sometimes the mineral binders are added to improve mechanical resistance and durability. However, this effect was not proven and some studies claim this addition can increase water absorption and it has no significant effect on flexural and compressive strength $[1,4]$. Concerning the moisture buffering capacity, McGregor et al. found out that the soil selection is more important than changes in density, preparation method or stabilisation (e.g., by mineral binders) [5].

The possibility to use earth based materials to conserve historical earth constructions speaks also for cutting out lime or cement additives. Because in this case the most compatible material should be chosen for conservation [4].

This eco-efficient material is used more often nowadays. The scientists (e.g., Gomes, Santos, Faria, et al.) tried to examine the characteristics of the material, but there is still a place for further research. This study is focused on evaluation of biological susceptibility of earth plasters. The most relevant factors influencing the growth of mould are temperature and relative humidity of the environment. The presence of fungi can lead to respiratory problems or allergies of the occupants of the buildings. Apart from external conditions, the intrinsic properties, such as po-

This is an open-access article distributed under the terms of the Creative Commons Attribution-NonCommercial 4.0 International License (https://creativecommons.org/licenses/by-nc/4.0/), which permits unrestricted use, distribution, and reproduction in any medium for non-commercial purposes, provided the original author and source are credited, a link to the CC License is provided, and changes - if any - are indicated. 
rosity, $\mathrm{pH}$ and chemical composition, also affect the bio-susceptibility [2]. The addition of natural fibres may also contribute to microorganism proliferation [3].

For our experiment we chose four types of earth plasters containing three types of plant fibres. First, the naturally occurring species of mould and bacteria were identified. Subsequently, the microbiological resistance of the plasters depending on relative humidity was evaluated.

\section{Materials and calculation methods}

Four types of earth plasters were selected for the experiment. They consist of natural clay, sand and plant fibres. Each of the plasters contained different type of organic fibre, the fourth plaster was made using all the fibres which appeared in the composition of three previous plasters - oat straw, hemp and cellulose (Table 1).

Table 1. Description of the samples and the fibre content

\begin{tabular}{lll}
\hline Samples & Type of natural fibre & Coarseness of fibres \\
\hline A & Oat straw & Coarse \\
B & Hemp & Fine \\
C & Cellulose & Fine \\
D & Oat straw, hemp, cellulose & Coarse \\
\hline
\end{tabular}

\subsection{Identification of naturally occurring species}

The dry and loose sample of each earth plaster weighing $100 \mathrm{mg}$ was placed to Petri dishes with a broth made of Czapek Dox agar (Fluka, Germany). The samples were then incubated for 7 days in a temperature $23 \pm 2{ }^{\circ} \mathrm{C}$. The specimens of grown mould were removed and observed in the optical microscope Olympus BX 41. Based on the observation of significant signs, the genera of the mould were identified. (Samson et al., 2010)

The bacteria, which appeared on the Petri dish along with the mould, were removed and inoculated on meat peptone agar (PLab, Czech Republic). After 3 days in $30 \pm 2{ }^{\circ} \mathrm{C}$ the bacteria were identified using identification kit NEFERMtest 24 (Lachema, Czech Republic) based on biochemical reactions colourations.

\subsection{Determination of boundary conditions for fungal growth}

During the experiment two ways of application were simulated. First set of samples was made by mixing with water and dried in $23 \pm 2{ }^{\circ} \mathrm{C}$ and relative humidity below $25 \%$. The second set of samples were made in the same conditions but dried in higher relative humidity reaching $65 \%$.

After two days of drying, the samples were placed in five different desiccators. The saturated solution of a different salt was poured to the bottom of each container, so the samples were placed in five different environments with relative humidity ranging from $33 \%$ to $100 \%$.

Both sets of samples were kept in these conditions for 4 weeks. They were evaluated every week according to the modified technical standard CSN EN ISO 846. Evaluation was performed visually and microscopically, giving each sample a number on a scale $0-5$ based on the fungal growth rate (Table 3).

\section{Results}

\subsection{Identification of naturally occurring species}

The genera of the mould naturally occurring in all four types of earth plasters were determined microscopically. The results in Table 2 show that Alternaria sp. was found in three types of plaster. The second most common genus was Penicillium sp. identified in sample $\mathrm{A}$ and $\mathrm{C}$.

Table 2. Identification of naturally occurring moulds

\begin{tabular}{ll}
\hline Samples & Genera of the identified mould \\
\hline $\mathrm{A}$ & Alternaria sp., Fusarium sp., Penicillium sp. \\
$\mathrm{B}$ & Mucor sp., Trichoderma sp. \\
$\mathrm{C}$ & Alternaria sp., Penicillium $\mathrm{sp}$. \\
$\mathrm{D}$ & Alternaria $\mathrm{sp}$. \\
\hline
\end{tabular}

The following types of bacteria were represented in earth plasters: Sphingomonas sp., Sphingobacterium sp., Acinetobacter sp., Suttonella sp., Chrysobacterium sp. The first two genera of the bacteria were found in all the samples with high probability. These are bacteria commonly found in the nature, especially on plants, in soil and water.

\subsection{Determination of boundary conditions for fungal growth}

After 2 days of drying in RH below $25 \%$ or in $65 \%$, the samples were placed in 5 desiccators with different relative humidity. The samples were then evaluated every week and numbered according to the scale shown in Table 3.

Table 4 shows evaluation of the samples dried below $25 \% \mathrm{RH}$, which were distributed to relative humidity reaching $33 \%, 50 \%, 58 \%, 64 \%$ and $84 \%$. Three samples were observed in each category and their resulting values were averaged. The plaster D (contain- 


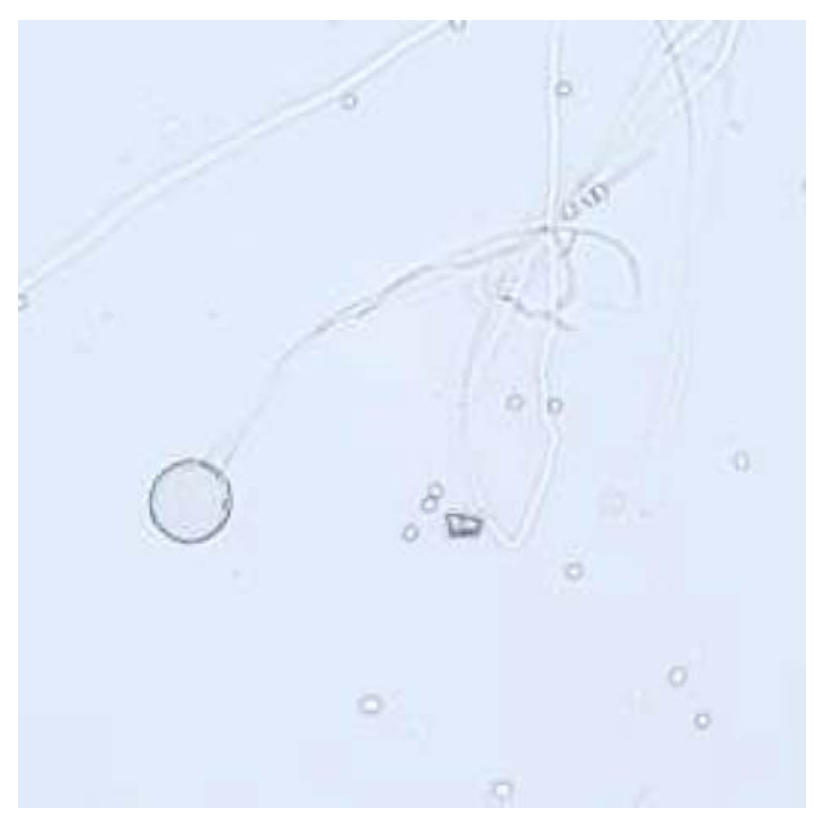

Fig. 1. Mucor sp., magnification $400 \times$

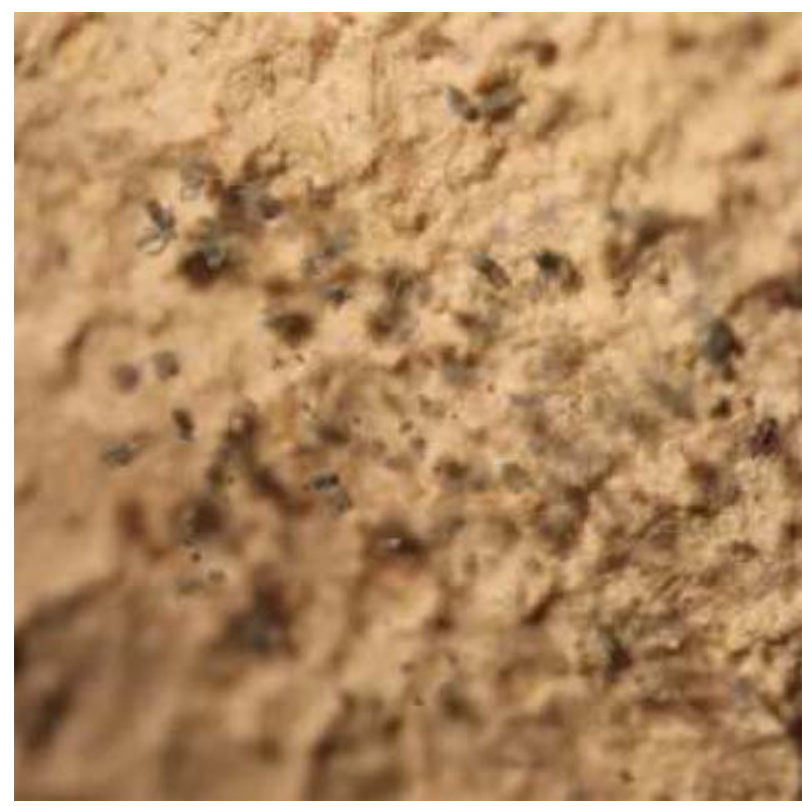

Fig. 3. Sample D dried below $25 \% \mathrm{RH}$, documented after 2 weeks in RH $84 \%$, magnification $100 \times$, grey fungal colonies visible

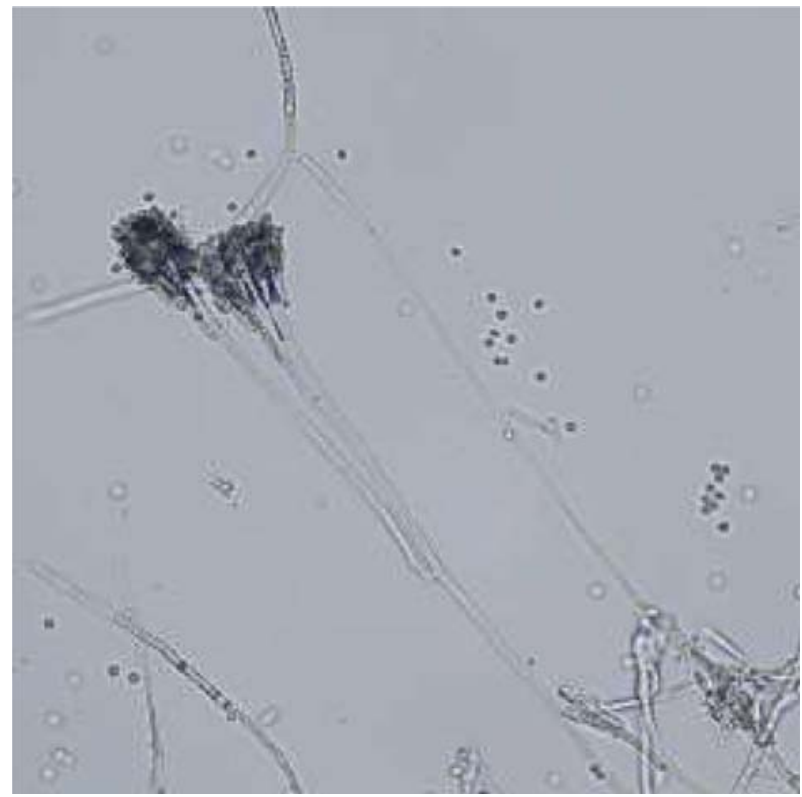

Fig. 2. Penicillium sp., magnification $400 \times$

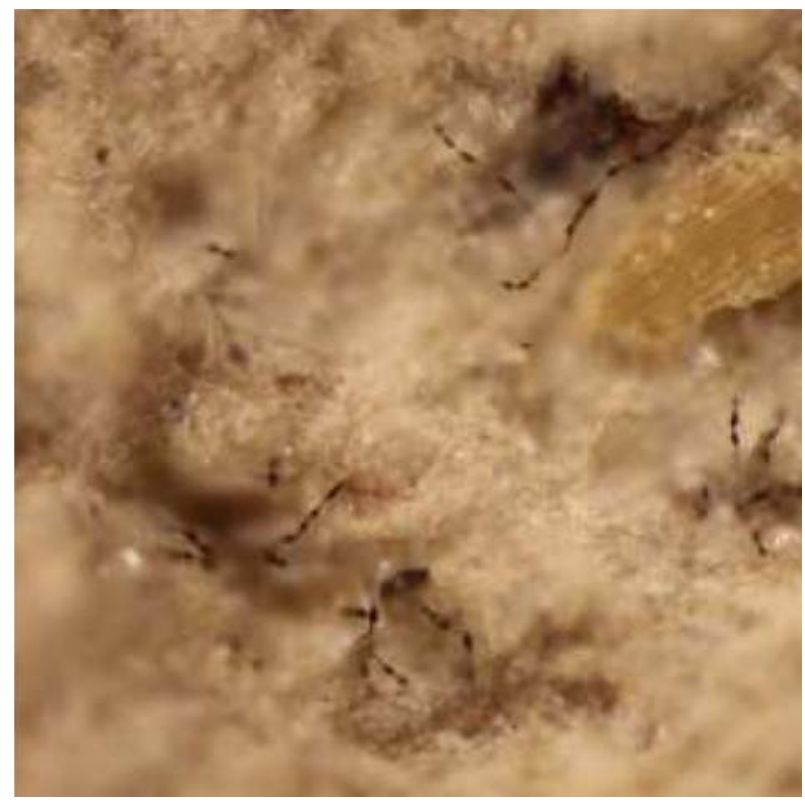

Fig. 4. Sample D dried below $25 \% \mathrm{RH}$, documented after 4 weeks in RH $84 \%$, magnification $100 \times$, colonies of Alternaria sp. visible

Table 3. A scale used for fungal growth rate evaluation

\begin{tabular}{cl}
\hline Fungal growth rate & \multicolumn{1}{c}{ Evaluation } \\
\hline 0 & No growth visible under a microscope \\
{$[1]$} & First signs of growth detectable under a microscope \\
1 & Separate fungal colonies detectable only microscopically \\
2 & Growth visible to the naked eye covering up to $25 \%$ of the surface \\
3 & Growth visible to the naked eye covering up to $50 \%$ of the surface \\
4 & Significant growth covering more than $50 \%$ of the test surface \\
5 & Growth covering the entire test surface \\
\hline
\end{tabular}


Table 4. Evaluation of samples dried below $25 \%$ relative humidity

\begin{tabular}{|c|c|c|c|c|c|}
\hline \multirow{2}{*}{ Plaster } & \multirow{2}{*}{$\mathrm{RH}[\%]$} & \multicolumn{4}{|c|}{ Days } \\
\hline & & 7 & 14 & 21 & 28 \\
\hline \multirow{5}{*}{ A } & 33 & {$[0.66]$} & {$[0.66]$} & {$[0.66]$} & {$[0.66]$} \\
\hline & 50 & 0 & 0 & {$[0.66]$} & {$[0.33]$} \\
\hline & 58 & {$[0.33]$} & 0 & {$[0.66]$} & 0 \\
\hline & 64 & 0 & {$[0.33]$} & {$[0.66]$} & [1] \\
\hline & 84 & 0.66 & {$[0.66]$} & 0.66 & 0.66 \\
\hline \multirow{5}{*}{ B } & 33 & 0 & 0 & 0 & 0 \\
\hline & 50 & 0 & 0 & 0 & 0 \\
\hline & 58 & 0 & 0 & 0 & 0 \\
\hline & 64 & 0 & 0 & 0 & 0 \\
\hline & 84 & 0 & {$[0.33]$} & 1 & 1 \\
\hline \multirow{5}{*}{$\mathrm{C}$} & 33 & 0 & 0 & 0 & 0 \\
\hline & 50 & 0 & 0 & 0 & 0 \\
\hline & 58 & 0 & 0 & 0 & 0 \\
\hline & 64 & 0 & 0 & 0 & 0 \\
\hline & 84 & 0.66 & 1 & 1 & 1 \\
\hline \multirow[t]{5}{*}{$\mathrm{D}$} & 33 & {$[0.33]$} & {$[0.33]$} & 1 & 1 \\
\hline & 50 & {$[0.33]$} & [0.33] & {$[0.66]$} & {$[0.66]$} \\
\hline & 58 & {$[0.33]$} & [0.33] & {$[0.66]$} & [1] \\
\hline & 64 & 0 & 0 & {$[0.33]$} & {$[0.33]$} \\
\hline & 84 & 1 & 1 & 1.33 & 1.66 \\
\hline
\end{tabular}

Table 5. Evaluation of samples dried in $65 \%$ relative humidity

\begin{tabular}{|c|c|c|c|c|c|}
\hline \multirow{2}{*}{ Plaster } & \multirow{2}{*}{$\mathrm{RH}[\%]$} & \multicolumn{4}{|c|}{ Days } \\
\hline & & 7 & 14 & 21 & 28 \\
\hline \multirow{5}{*}{ A } & 33 & 2 & 2 & 2 & 2 \\
\hline & 50 & 2 & 2 & 2 & 2 \\
\hline & 64 & 2 & 2 & 2 & 2 \\
\hline & 84 & 1.66 & 2 & 1.66 & 1.66 \\
\hline & 100 & 1.33 & 2 & 1.66 & 1.33 \\
\hline \multirow{5}{*}{ B } & 33 & [1] & [1] & 1 & 1 \\
\hline & 50 & [1] & {$[1]$} & {$[1]$} & [1] \\
\hline & 64 & [1] & {$[1]$} & 1 & {$[1]$} \\
\hline & 84 & {$[1]$} & {$[1]$} & {$[1]$} & [1] \\
\hline & 100 & 1 & 1 & 1 & 1 \\
\hline \multirow{5}{*}{$\mathrm{C}$} & 33 & 1.33 & 1.33 & 1.66 & 1.66 \\
\hline & 50 & 2 & 1.66 & 1.66 & 1.66 \\
\hline & 64 & 2 & 2 & 2 & 2 \\
\hline & 84 & 2 & 2 & 2.33 & 2 \\
\hline & 100 & 2 & 3 & 3 & 3 \\
\hline \multirow{5}{*}{$\mathrm{D}$} & 33 & 2 & 2 & 1.66 & 1.66 \\
\hline & 50 & 2 & 2 & 2 & 2 \\
\hline & 64 & 2 & 2 & 2 & 2 \\
\hline & 84 & 2 & 2 & 2 & 2 \\
\hline & 100 & 2 & 3.33 & 3.33 & 3.33 \\
\hline
\end{tabular}




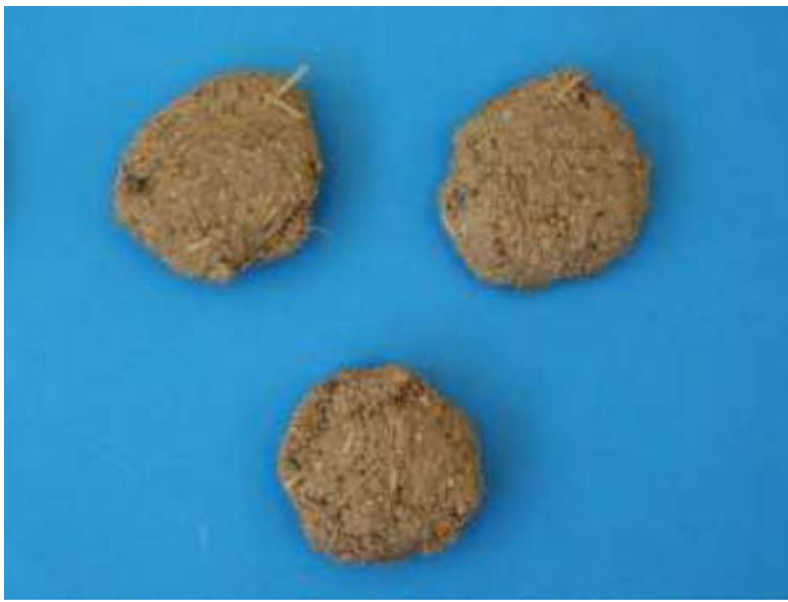

Fig. 5. Samples of plaster A dried in $65 \% \mathrm{RH}$, then placed in $100 \% \mathrm{RH}$ for 4 weeks

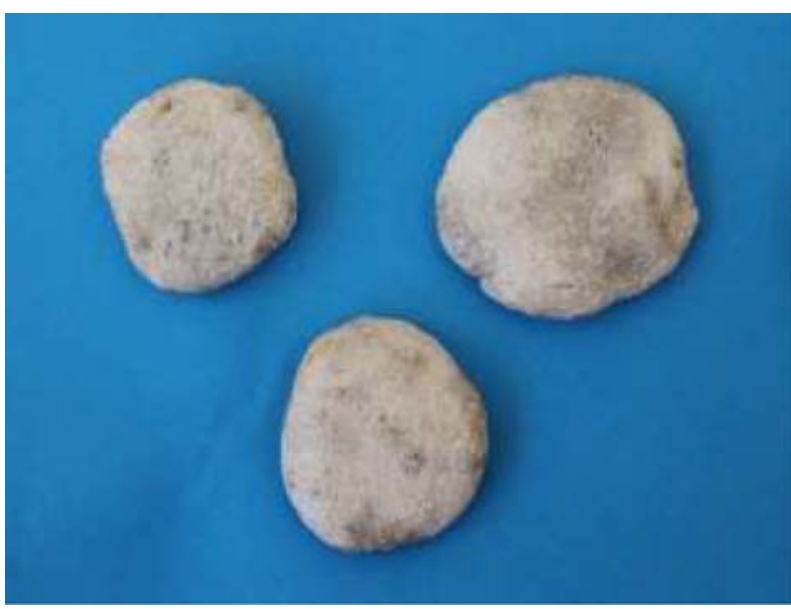

Fig. 7. Samples of plaster $\mathrm{C}$ dried in $65 \% \mathrm{RH}$, then placed in $100 \% \mathrm{RH}$ for 4 weeks

ing three types of plant fibres) showed the lowest resistance to fungal growth as in all the environments the colonies of mould started to occur in all the samples. In the highest RH equalling $84 \%$, the mould was even detectable by naked eye. The samples made of plaster A (with oat straw addition) had the similar fungal growth rate in all the values of relative humidity. The plaster B and C did not show any growth except in the highest $\mathrm{RH}$, where the mould was visible only under a microscope.

Evaluation of samples dried in $65 \% \mathrm{RH}$ is in $\mathrm{Ta}-$ ble 5 . The samples were also placed in 5 desiccators with different relative humidity $-33 \%, 50 \%, 64 \%$, $84 \%$ and $100 \%$. The most resistant was the plaster B (with addition of hemp), where the fungal growth was detectable only under a microscope independently of the relative humidity. The plasters $\mathrm{C}$ and $\mathrm{D}$ received the highest numbers among all the plasters. The fungal growth rate ranged around value 2 in most of the environments and in the highest relative humidity the

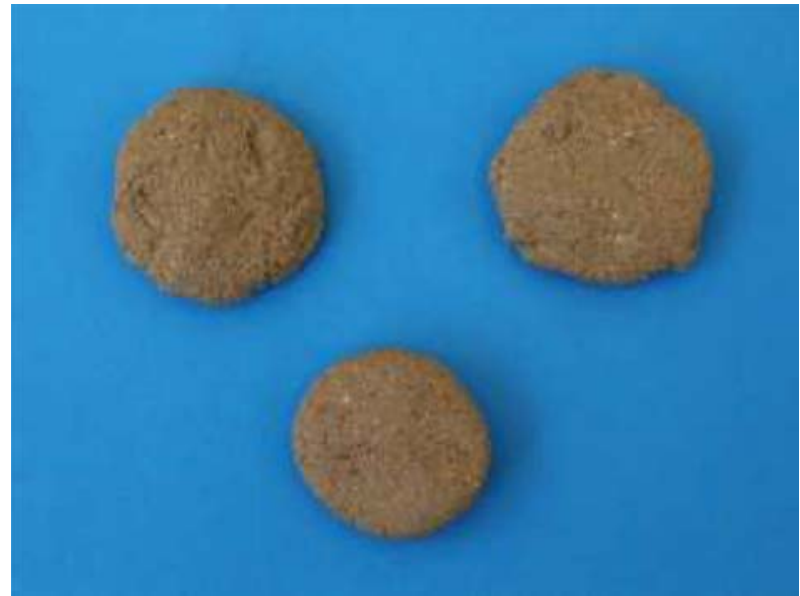

Fig. 6. Samples of plaster $\mathrm{B}$ dried in $65 \% \mathrm{RH}$, then placed in $100 \%$ RH for 4 weeks

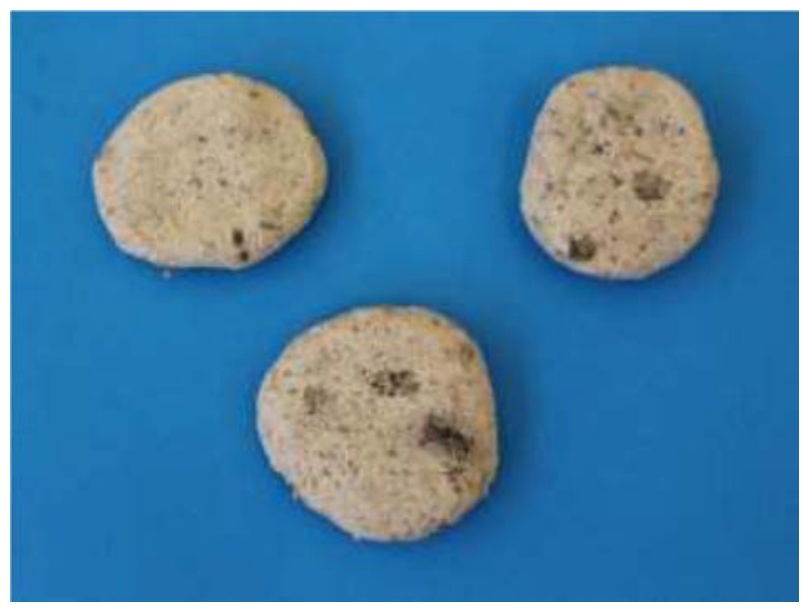

Fig. 8. Samples of plaster D dried in $65 \% \mathrm{RH}$, then placed in $100 \% \mathrm{RH}$ for 4 weeks

rate reached value 3 , which means the surface of the samples was covered up to $50 \%$. The photodocumentation of all samples placed in $100 \% \mathrm{RH}$ is shown in Figs 5-8.

\section{Discussion}

The results show a significant dependence of fungal growth rate on conditions during the application of the plasters, in this case the relative humidity. The samples which were dried in the relative humidity below $25 \%$ for 2 days showed smaller extent of mould than the samples dried in higher relative humidity. This result proves that moisture is one of the most relevant factors influencing the occurrence of microorganisms [2]. If we compare placing the samples after drying in 5 desiccators with different relative humidity ranging from $33 \%$ to $100 \%$, the highest values of fungal growth rate were noted in $100 \% \mathrm{RH}$ according to our expectation. The values of samples placed in the rest 
of the desiccators with lower humidity were similar to each other.

Another topic to observe is the type of plant fibre added to the mixture and its coarseness. The plasters B and $\mathrm{C}$ from the first set of samples (dried in lower $\mathrm{RH}$ ) were the most resistant to microbial attack. As both plasters contain finely chopped fibres, the results indicate that the mould grow easier on plasters with coarse fibres. However, the values of the second set of samples (dried in 65\% RH) do not follow this conclusion. The question is also the type of the fibres. The lowest values of fungal growth rate in both sets of samples were measured on the plaster B with addition of hemp. This topic would nevertheless require further research. Laborel-Préneron et al. [3] mentioned in their study that the moulds are observed more often when plant fibres are present in the material. According to our observation under a microscope the colonies of mould started to grow around the fibres in most cases, as the plant fibres are organic and able to absorb moisture.

\section{Conclusion}

This study was focused on the influence of relative humidity on fungal growth rate of earth plasters. We observed the created samples of plasters in different values of relative humidity during the drying of the samples, simulating the application conditions, as well as during the period of four weeks after the application. The conditions during the application seem to be crucial in terms of microbiological activity. When the relative humidity is lower, the probability of fungal growth is decreased. The impact of the conditions in the first few days after application is critical and it is important to let the plaster to dry entirely. The relative humidity after drying does not have to be controlled with such caution.

\section{Acknowledgements}

This work was supported by a student grant SGS18/166/OHK1/3T/11. The authors also acknowledge the company Picas for providing the samples of earth plasters.

\section{References}

[1] Gomes M., Faria P., Gonçalves T. (2018), Earth-based mortars for repair and protection of rammed earth walls. Stabilization with mineral binders and fibers. Journal of Cleaner Production, 172, 2401-2414.

[2] Santos T., Nunes L., Faria P. (2017), Production of eco-efficient earth-based plasters: Influence of composition on physical performance and bio-susceptibility. Journal of Cleaner Production, 167, 55-67.

[3] Laborel-Préneron A., Aubert J., Magniont C., Tribout C., Bertron A. (2016), Plant aggregates and fibers in earth construction materials: A review. Construction and Building Materials, 111, 719-734.

[4] Gomes M., Gonçalves T., Faria P. (2016), Hydric behavior of earth materials and the effects of their stabilization with cement or lime: Study on repair mortars for historical rammed earth structures. Journal of Material in Civil Engineering, 28(7), 04016041.

[5] McGregor F., Heath A., Shea A., Lawrence M. (2014), The moisture buffering capacity of unfired clay masonry. Building and Environment, 82, 599-607.

[6] Samson R. A., Houbraken J., Thrane U., Frisvad J. C., Andersen B. (2010), Food and Indoor Fungi. Utrecht: CBSKNAW Fungal Biodiversity Centre, 390 p. (CBS Laboratory Manual Series). 